\title{
Protein Deficiency and the Growing Rat Lung. I. Nutritional Findings and Related Lung Volumes
}

\author{
MASENDU KALENGA, ${ }^{1}$ STEFAN A. TSCHANZ, AND PETER H. BURRI \\ Institute of Anatomy, Section of Developmental Biology, University of Berne, \\ CH-3000 Berne 9, Switzerland
}

\begin{tabular}{|c|c|}
\hline ABST & $\mathbf{R A C T}$ \\
\hline $\begin{array}{l}\text { We investigated the consequences of early malnutrition on } \\
\text { milk production by dams and on body weight and structural lung } \\
\text { growth of young rats using two models of protein restriction. } \\
\text { Dams of the early restriction group were fed an } 8 \% \text { casein diet } \\
\text { starting at parturition. Those of the delayed restriction group } \\
\text { received a } 12 \% \text { casein diet from lactation d } 8-14 \text { and thereafter } \\
\text { the } 8 \% \text { diet. After weaning, early restriction and delayed restric- } \\
\text { tion group rats were maintained on low protein until d } 49 \text {, then } \\
\text { refed the control diet ( } 18 \% \text { casein) up to d } 126 \text {. Milk was } \\
\text { analyzed on } \mathrm{d} 12 \text {. Animals were killed at d } 21,49 \text {, and } 126 \text { for } \\
\text { lung fixation in situ. In this report, we show that protein restric- } \\
\text { tion lowered milk yield to } 38 \% \text { of normal. Milk lipid per gram of } \\
\text { dry weight tended to be increased, whereas lactose and protein } \\
\text { were significantly decreased. Pups from protein-restricted dams }\end{array}$ & 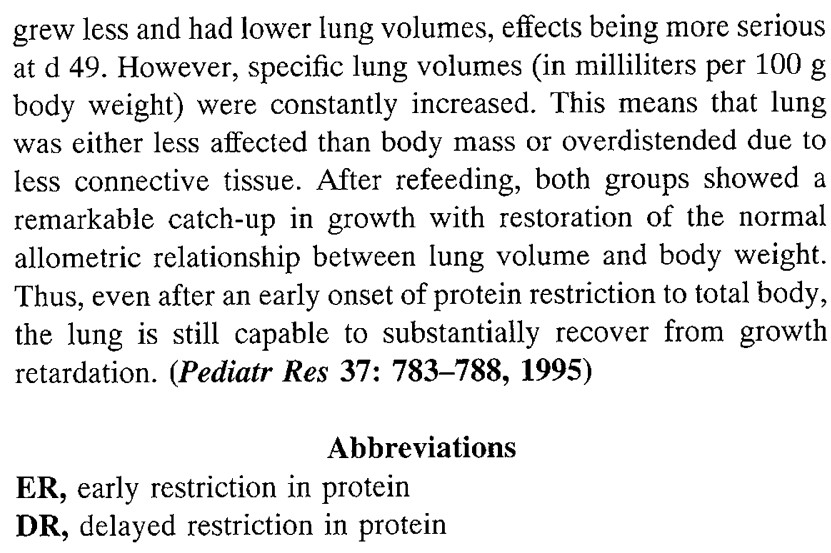 \\
\hline
\end{tabular}

From experimental studies in animals, it is well documented that food deficiencies result in growth retardation along with functional alterations of the lung. Two recent publications have substantially reviewed the literature on the topic $(1,2)$. The majority of studies have concerned the rat because in this species the different processes of growth and development of the lung are well characterized (3-6). In this respect, critical transformations of the lung parenchyma in the postnatal period corresponding to the developmental steps of alveolization and microvascular maturation occur before the age of $3 \mathrm{wk}$. In normal conditions, the volume of the lung is largely determined by the dimension of the thoracic cage, which in turn depends allometrically on the body mass of the rat (7). Similarly, the quantitative parameters of the various components of the parenchyma are known to be related to lung volume (4). All of these lung parameters also vary with both the metabolic needs and the $\mathrm{O}_{2}$ demands of the organism (8) and the $\mathrm{O}_{2}$ in the ambient air (9).

The effects on the rat lung of malnutrition beginning during the neonatal period (i.e. the period of suckling) are not well

Received June 28, 1994; accepted December 12, 1994.

Correspondence: Peter H. Burri, M.D., Institute of Anatomy, Bühlstrasse 26, Postfach 139, CH-3000 Berne 9, Switzerland.

Supported by grant $3100-36530.92$ from the Swiss National Science Foundation.

${ }^{1}$ Supported by a fellowship from Nestlé-Nutrition/Switzerland. Present address: University of Louvain, UCL/ENDO 5530, Av Hippocrate 55, B-1200 Brussels, Belgium. known. A study by Winick and Noble (10) showed that underfeeding suckling rats by litter enlargement throughout the lactation period resulted in decreased lung weight and lung DNA content at weaning; these findings persisted after a 16-wk period of normal feeding. Shorter durations of underfeeding or starvation (2-14 d) at various times in the neonatal period have also resulted in alteration of the rat lung growth as suggested by morphologic and biochemical changes (11-13). So far, no study investigating longer durations of controlled malnutrition starting during the neonatal period have dealt with the induced changes in the quantitative lung parameters and in their allometry.

Furthermore, although human malnutrition is not precisely defined and is not exactly reproducible in experimental animals, it is obvious that, in many areas of developing countries, low protein intake by lactating mothers and infants is one of the major causes of childhood nutritional disorders. Kwashiorkor, a widespread malnutrition syndrome among children younger than $4 \mathrm{y}$, is the typical picture of protein deficiency. In previous reports, one of us had shown from weight and DNA determinations that lung growth in the rat was more negatively affected by protein restriction starting during the neonatal period (14) than by that beginning after weaning (15). Moreover, the neonatally restricted rats had overdistensible lungs upon saline filling. 
The present study was undertaken to provide further information on the consequences of protein restriction on the rat lung during early life and the effects of refeeding. The whole study comprised the determination of the lung volume with respect to body weight and the quantitative structural analysis of the lungs by means of morphometric techniques. In this first report, we present a set of results comprising nutritional observations in our model that was designed to resemble early protein energy deficiency in children. Hence, alterations in the lactational performance of dams and their effects on the growth of offspring were analyzed. Further, because malnutrition is accompanied by a reduction in basal metabolic rate, and hence in $\mathrm{O}_{2}$ consumption (16), we wondered also whether the allometric relationship between lung dimensions and body weight was affected. In the jointly published companion study (17) we discuss the structural and functional changes as determined by morphometric methods in the lungs of these same animals.

\section{METHODS}

Animals. Timed pregnant SIVZ50 albino rats (first parity) were housed individually in wire-bottomed cages at constant room temperature and humidity. They were exposed to a 12-h light-dark cycle. Delivery always occurred between gestational d 21 and 22, and the day of birth was considered as postnatal $\mathrm{d} 1$ or lactation d 1 . At lactation d 2, litter size was standardized to eight pups (all males) for all groups. Weaning was carried out at lactation d 21, after which the rats were maintained in groups of four per cage. Body weight of the lactating mothers was determined at lactation d 2, 12, and 21. Individual body weights of the pups were measured for the first time at $\mathrm{d} 8$ and thereafter twice a week until d 49, then once a week.

Diets. All groups had free access to a pelleted food (Kliba AG, Switzerland) and to water throughout the experiment. The protein content of the diets was either normal (18\% casein) or restricted (12 or $8 \%$ casein). However, their caloric density was kept constant at $2.9 \mathrm{kcal} / \mathrm{g}$ by adjusting the proportion of carbohydrates. Dams were randomly assigned to different dietary groups, and thereafter the pups were maintained on the same diets. The nutritional protocol comprised two test groups: an ER and a DR group. The ER group received an $8 \%$ casein diet from parturition (or birth) until d 49, and the DR one was fed a $12 \%$ casein diet from lactation $\mathrm{d} 8-14$, and then given the $8 \%$ casein diet until d 49 (Fig. 1). Among the ER rats, two singular groups (derived from two different litters) differed so much in body weight from the ER population that they had to be considered separately on the basis of statistical considerations. One group on d 21 was much larger (large ER), whereas another on d 49 was much smaller (small ER). The three small ER rats originated from a litter of which five animals died within $48 \mathrm{~h}$ after weaning.

One of us had previously used the DR model to obtain biochemical and mechanical data $(14,18)$, and we wanted to assess the lung structural changes correlated with those experiments. At the time that approach had been applied to reflect the progressive onset of the nutritional deficiency in some human conditions (19). From postnatal d 49 up to d 126, some rats of the ER and the DR groups were refed with the normal

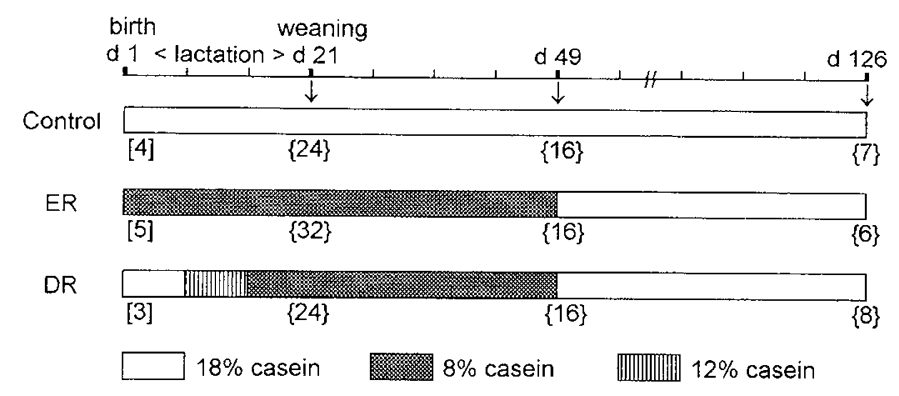

Figure 1. Graphic representation of the nutritional protocol of the study. Horizontal bars show the time axis. $[n]$ indicates litter number and $\{n\}$ the number of rats in the group at the corresponding age. Pups were not prevented from eating the maternal food and were maintained on the same diet after weaning. One control litter was excluded for maternal cannibalism at lactation $\mathrm{d}$ 6. The ER group does not include the singular large ER rats at $\mathrm{d} 21$ and small ER ones at d 49. Arrows indicate time points of lung fixation.

diet (18\% casein) that was given to a control group throughout the experiment.

Mother food intake and lactational performance. Inasmuch as solid food consumption by suckling pups occurs by the end of the second lactation week (20), mothers' daily food intake and milk production and composition were estimated by midlactation. For these measurements, the DR group that had not yet experienced a long period of protein restriction at this point was not considered. We thus only had to compare the ER group with controls. The amount of food consumed by lactating dams was measured over a continuous period of $72 \mathrm{~h}$ (from d 9 to 12) and then divided by 3 to determine the daily food intake, hence that of calories and protein.

Milk yield was estimated in parallel groups by the method proposed by Grigor et al. (21) from the litter live weight gain between d 11 and 12 using the following formula: daily milk production $=$ litter live weight gain $+(0.08 \times$ the total litter live weight). The constant term 0.08 compensates for the daily weight loss by litters due to urine, feces, and perspiration. Samples of milk were obtained from the stomach of pups suckled for $1 \mathrm{~h}$ after a 4-h period of mother withdrawal as described by Fellows and Rasmussen (22). These samples were stored at $-20^{\circ} \mathrm{C}$ until lyophilization and biochemical analyses were performed. Milk lactose was measured enzymatically after deproteinization by use of $\beta$-galactosidase and $\beta$-galactose dehydrogenase (Boehringer-Mannheim Biochemicals, Indianapolis, IN) as described by Kurz and Wallenfels $(23,24)$. The protein content was determined by the combustion method of Dumas (cited in Ref. 25) on an automatic protein analyzer, type NA 1500 (Carlo Erba). Milk total lipids were extracted following the modified method of Mojonnier (cited in Ref. 26). Because it has been suggested that water content of the milk varies with the method of collection in underfed rats (22), values of milk components were expressed as percents of dry milk. The caloric density was calculated using the values of $4 \mathrm{kcal} / \mathrm{g}$ for proteins and lactose and $9 \mathrm{kcal} / \mathrm{g}$ for lipids.

Lung processing. The lungs of three to six animals per group were fixed by intratracheal instillation using a standard procedure (4). Briefly, the rats were anesthetized with a mixture of Vetranquil (acepromazinum, $0.06 \mathrm{mg} / 100 \mathrm{~g}$ body weight), Xylapan (xylazinum, $0.6 \mathrm{mg} / 100 \mathrm{~g}$ body weight), and 
Narketan (ketaminum, $6 \mathrm{mg} / 100 \mathrm{~g}$ body weight). After median laparatomy, the hemidiaphragms were punctured to induce lung collapse; then the trachea was cannulated and the lung inflated with $2.5 \%$ glutaraldehyde in $0.03 \mathrm{M}$ potassium phosphate buffer at a constant pressure of $20 \mathrm{~cm}$ of water above the chest. After a brief stabilization of flow, the trachea was ligated; then the chest was opened by mid-thoracotomy, and the chest organs were excised en bloc and stored in the fixative for at least $24 \mathrm{~h}$ to allow for adequate tissue fixation before subsequent manipulations. Lung volume was determined by the submersion method (27). For each animal we also calculated the specific lung volume as total lung volume per $100 \mathrm{~g}$ body weight.

Statistical analysis. Data are presented as means \pm 1 SEM of the group. For each set of data, a one-way analysis of variance was carried out. The difference between means was assessed by multiple comparison with the Student-NewmanKeul's test (cited in Ref. 28). Data of the singular large and small ER animals were only compared with those of the standard ER rats of same age by a $t$ test. The significance level was set at $p<0.05$ for the two-tailed tests.

\section{RESULTS}

Mothers' food consumption, lactational performance, and body weights. Mean daily food intake from lactation d 9 to 12 and milk production and composition at $\mathrm{d} 12$ are shown in Table 1. Feeding lactating dams with low protein diet resulted in a reduction of food intake (hence of calorie consumption) to $31 \%$ of that of control rats. This was already apparent within the first days of consumption of the low protein diet (results not shown). It followed that their consumption of protein was only $14 \%$ of normal. As a consequence, malnourished dams yielded $38 \%$ of the milk quantity produced by controls. Milk production per consumed calorie was similar between control and ER dams, whereas the latter yielded almost three times the normal amount of milk per consumed gram of protein. Biochemical

Table 1. Lactating dams' food intake, body weight change, and milk production

\begin{tabular}{lrc}
\hline & $\begin{array}{r}\text { Control } \\
(n=3)\end{array}$ & $\begin{array}{c}\text { Early restriction } \\
(n=3)\end{array}$ \\
\hline Food intake & & \\
Food, g/d & $48.5 \pm 1.3$ & $15.2 \pm 2.2 \dagger$ \\
Calories/d & $140.6 \pm 3.8$ & $44.2 \pm 6.4 \dagger$ \\
Proteins, g/d & $8.7 \pm 0.2$ & $1.2 \pm 0.2 \dagger$ \\
Weight change d 2 to 12, \% & $-13.6 \pm 1.2$ & $-17.7 \pm 1.3 \ddagger$ \\
Milk yield on d 12 & & \\
Milk, g/d & $26.4 \pm 1.1$ & $10.0 \pm 1.1 \dagger$ \\
Milk, g/calorie intake & $0.2 \pm 0.0$ & $0.2 \pm 0.0$ \\
Milk, g/g of protein intake & $3.0 \pm 0.2$ & $8.4 \pm 1.2 \ddagger$ \\
Milk composition (dry weight) & & \\
Lipids, \% & $34.2 \pm 2.9$ & $41.0 \pm 1.2$ \\
Proteins, g\% & $37.8 \pm 0.2$ & $30.0 \pm 1.2 \dagger$ \\
Lactose, g\% & $5.1 \pm 0.1$ & $3.6 \pm 0.5 \ddagger$ \\
Caloric density, cal/100 g & $479.0 \pm 26.1$ & $503.1 \pm 9.8$ \\
\hline
\end{tabular}

Values are means \pm SEM for $n$ lactating dams. Protein restriction was started at parturition. Food consumption was measured during a 72 -h period from $\mathrm{d} 9$ to 12 , then daily consumption was calculated.

$\dagger p<0.01$.

$\ddagger p<0.05$ when compared to control value. analysis revealed that milk from malnourished rats tended to have a higher lipid content than that of controls $(p=0.05)$. In the opposite, its concentration in lactose and in protein was lowered by 29 and $21 \%$, respectively. The caloric density, however, was unaltered.

All dams tended to loose weight throughout the lactation period, with more pronounced effects in those restricted in protein. The greatest weight loss was observed in one ER dam with the heaviest offspring (large ER group) mentioned above ( $-38 \%$ versus $-27.1 \pm 4.0 \%$ for the three other dams).

Body weights and lung volumes of offspring. Body weight curves for control and experimental animals are presented in Figure 2. Figure 3 shows absolute and specific values of lung volumes.

Findings from $d 8$ to 21 (weaning). Mean individual weight of pups at $\mathrm{d} 8$ was significantly lower $(p<0.001)$ for the ER $(13.5 \pm 0.7 \mathrm{~g})$ compared with the control group $(16.4 \pm 0.5 \mathrm{~g})$. Body weight of rats of the DR group at $\mathrm{d} 8(16.3 \pm 0.4 \mathrm{~g})$ did not differ from that of controls. Although all pups gained weight from $\mathrm{d} 8$ to 21 , weight gain was less for pups nursed by dams fed the low protein diets. In the ER group, it appeared that malnutrition did not affect all litters to the same extent. As mentioned in "Methods," in one litter (large ER), mean pups" weaning weight $(26.3 \pm 0.4$; open triangle in Fig. $2 A)$ was significantly higher $(p<0.001)$ than that of the three other ER dams $(20.2 \pm 0.4)$.

Lung volumes were significantly lowered in all malnourished rats when compared with age-matched controls (Fig. $3 A$ ). However, as related to body weight, specific lung volumes were constantly increased under malnutrition (Fig. 3B). The greatest value was found in ER rats $(+28 \%$ above controls), whereas the increase was only $7 \%$ in the singular large ER group.

Findings at $d 49$. After weaning, some ER and DR rats were maintained on a low protein diet for a further $4 \mathrm{wk}$. During this period all rats gained weight, but weight gain of proteindeficient rats was less than half the control value (Fig. $2 A$ ). The

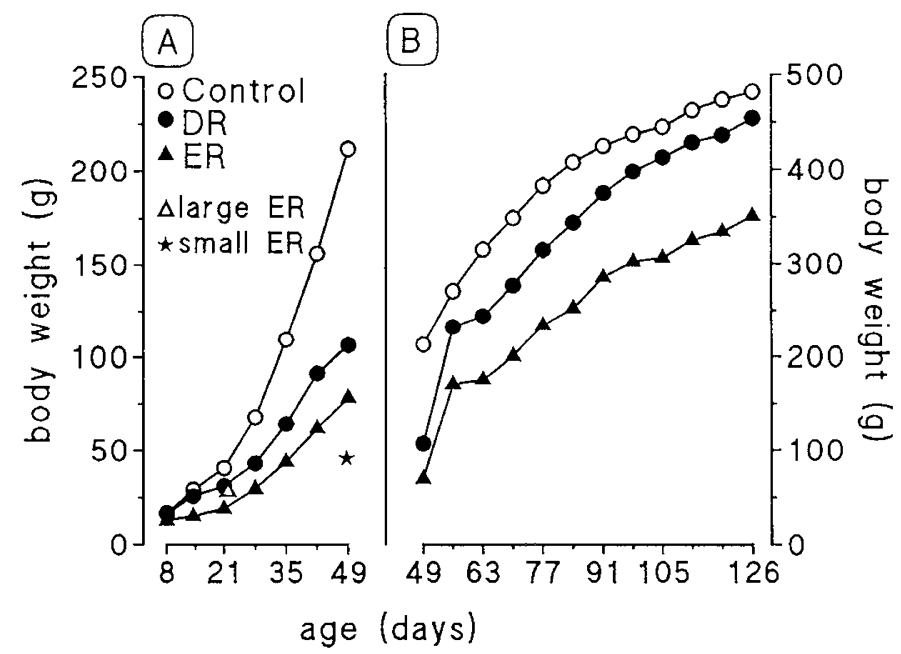

Figure 2. Growth curves of the control and the experimental groups. A, Protein restriction period; $B$, refeeding period. Number of animals per group as indicated in Figure $1 ; n=3$ for each of large and small ER groups. Notice the massive catch-up in body weight in the week after $d 49$. 

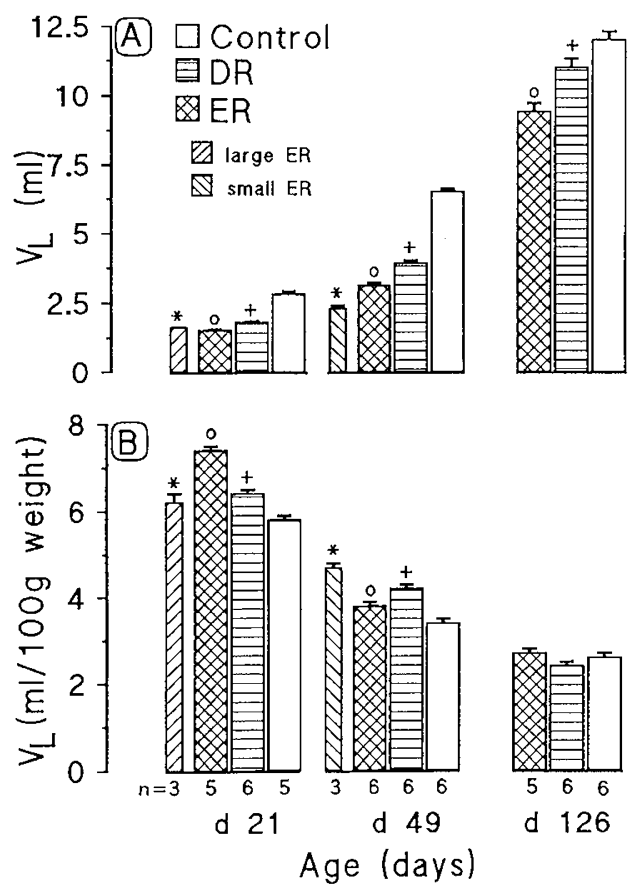

Figure 3. Lung volumes $\left(\mathrm{V}_{\mathrm{L}}\right)$ of the control and of the experimental groups. $A$, Absolute volumes; $B$, specific volumes; $\mathrm{d} 126$ corresponds to the end of an 11 -wk refeeding period. Column heights represent group means and error bars +1 SEM. Significance of differences between group means within same age group: $\bigcirc$, different from control and from DR group; + , different from control and from ER group; *, different from standard ER group.

lowest body weight was observed in the three small ER rats which reached only $61 \%$ of the value of the other ER rats (star in Fig. 2A).

Continuation of protein restriction up to $\mathrm{d} 49$ also resulted in a marked retardation in growth of the lung volumes (Fig. 3). However, malnourished rats still exhibited higher specific lung volumes than controls. In comparison with the standard ER rats aged $49 \mathrm{~d}$, small ER ones had a $21 \%$ lower absolute lung volume, whereas their specific lung volume was $39 \%$ higher. The macroscopic appearance of the lungs of malnourished animals was normal.

Findings after refeeding (d 126). After adequate refeeding, previously malnourished rats had dramatically increased their body weight (Fig. 2B). Refed DR rats had even gained 25\% more weight than controls. The most striking changes had occurred at the end of the first week of refeeding where all experimental rats had more than doubled their previous weight. It resulted that DR rats had almost completely caught up in body weight, whereas ER rats still had a $28 \%$ lower body weight when compared with age-matched controls.

As indicated by lung volumes, refeeding had also led to a significant lung regrowth (Fig. $3 A$ ), but the remaining difference from controls was still more evident in refed ER rats $(-22 \%)$ than in refed DR ones $(-8 \%)$. Both experimental groups, however, had completely normalized regarding the specific lung volumes.

\section{DISCUSSION}

This study provides additional information to the previous work of one of us on the alterations in lung parameters induced by protein restriction beginning during the lactation period (14, 18). We report that isocaloric reduction of the protein content of the diet leads to a dramatic decrease in the food consumption of lactating rats. Therefore, despite a normal caloric density of the food, the nutritional state induced was one of proteinenergy deficiency. Low food consumption in rats given a low protein diet during lactation is a common finding $(21,29,30)$. The causes of such a food intake depression are not fully understood. Recently, Friggens et al. (30) hypothesized that the low capacity of lactating rats to dispose of heat was the constraining factor of food intake. Furthermore, as a vicious circle, glucose shortage resulting from low food consumption and subsequent massive lipolysis may induce ketosis, which in turn depresses both appetite and milk production. In our study, the reduction in food intake observed within the first $3 \mathrm{~d}$ of protein restriction indicates a more rapid protein-dependent signal.

Upon malnutrition, the lactating rats had a significantly depressed milk yield. Both energy and protein restriction have been shown to reduce milk output in dams (21, 29-33). In our experiment, although lack of protein was the primary deficit, milk production appeared more regulated by calories than by protein intake, as indicated by the similar milk yield per calorie consumed in control and ER groups (Table 1). However, at a constant energy restriction, milk yield was negatively affected by the low protein content of the diet (33). These findings point to the complex complementarity between protein and energy supplies in nutritional processes. Although less agreement on the subject exists in human observations, it seems that lactation is more compromised in areas where protein deficiency prevails (34). Indirect support to this statement comes from increase in milk production and in baby weight gain after protein supplementation in poorly nourished lactating mothers (34).

More controversial are the reported alterations in the milk composition under energy or protein deficiencies. Previous studies have reported that protein restriction in lactating rats resulted in an increased lipid content $(31,32)$ and a decreased protein content (32). Warman and Rasmussen (33) have shown that food restriction by $50 \%$ of ad libitum intake during lactation resulted in higher concentrations of lipid and of protein, but in lower lactose content at $\mathrm{d} 14$. However, Grigor et al. (21) did not find any difference in the major components of the rat milk after energy restriction $(80,60$, or $40 \%$ of $a d$ libitum food intake) or protein restriction (10 versus $20 \%$ casein) from lactation d 7 to 14 . Similar discrepancies are observed in human studies (34). These variations probably result from dissimilarities in timing and methods of milk sampling and milk analysis as well as in differences in nutritional protocols. In our study applying protein restriction at parturition, both lactose and milk protein content were significantly depressed. However, because of a trend to a higher lipid concentration, the caloric density of the milk was unaltered. Anyway, it seems evident that decreased milk quantity had by far a greater effect on the growth rate of offspring than did alteration in milk quality. In this respect, we suspect that the single large ER group did better because their mother produced more milk at the cost of her body weight. Such a finding, even limited to a single dam, is consistent with some human obser- 
vations where many marginally nourished women can successfully achieve lactation at the expense of their health (35).

To determine the lung dimensions, we measured the lung volumes after instillation of the fixative into the airways of deeply anesthetized animals with unopened chests. This procedure, more appropriate for histologic studies, has the advantage to reflect the in vivo configuration of the lung. As expected, growth of the lung volume was reduced under malnutrition. However, because of a persistently increased specific lung volume, it is clear that lung size and body mass were not affected in the same way. Two possible mechanisms could have been involved in the disruption of the allometric relationship between lung volume and body weight.

First, malnutrition could have more negatively affected accumulation of less essential tissues like fat and skeletal muscles at the benefit of more vital organs. This assumption could be supported by our finding that specific lung volume was higher in animals more severely affected by malnutrition (e.g. variations among ER rats). In a previous study using the DR model, however, no increase in the specific lung weight or lung DNA in support of this preservation hypothesis was found (14). Therefore an alternative explanation could be that, subsequently to protein restriction, the terminal air spaces of the lung were overdistended in an emphysematous manner. Increased distensibility of malnourished rat lungs upon saline filling has been demonstrated in a DR model (14) and in many other conditions of food restriction (36-40).

One of the problems in assessing the allometry between lung size and body weight under malnutrition resides in the use of different approaches to measure lung size (wet or dry weight, maximal inflation volume, or submersion volume of the fixed lung). In 14-d-old rat pups that had been starved on $\mathrm{d} 1$ and 5, Das (12) reported an increased specific lung weight comparatively to age-matched controls. In adult rats subjected to severe nutritional depletion $(30-40 \%$ loss of their initial body weight), the most commonly reported pattern is an increase in the specific values of lung weights and of lung volumes ( 36 , $38,39)$. These findings have been related to the loss in tissue recoil with a dilatation of the air spaces (36) and to a higher tissue depletion in the whole organism than in the lung (39). It is interesting to notice that adult rats given two thirds of the normal amount of food for $6 \mathrm{wk}$, in a manner to keep body weight constant, had unchanged specific lung weight and lung volume (39). Similarly, in weanling rats fed an $8 \%$ casein diet for 4 wk and in which final body weight was only decreased by $10 \%$, both absolute and specific lung volumes were unaltered, although lung collagen and elastin concentrations were decreased (40). Because in some models the use of severe nutritional depletion (37-39) fixation was carried out by liquid instillation in excised lungs, an overdistension of the lung parenchyma containing less connective tissue could have occurred. This is likely to be true in the study by Harkema et al. (41), where severely malnourished adult rats (45\% weight loss) had a normal specific lung weight, but a $67 \%$ increase in the specific lung volume when compared with controls. After this review of the literature, it is obvious that changes in the allometric relationship between lung and body weight depend on multiple factors: the lung parameter studied, the technical procedures involved, the time of onset, and the severity of malnutrition.

After 11 wk of refeeding with control diet, previously malnourished rats showed a significant increase in body weights and lung volumes. The relative gain was even greater than in control animals. Although regrowth was not fully achieved in all rats at the end of the refeeding period, it is noteworthy that the normal allometric equilibrium between lung volume and body size was restored. Failure to catch up completely for absolute lung volume, particularly in refed ER rats, is in accordance with low lung weight and lung DNA content in rats underfed during lactation and refed for $16 \mathrm{wk}$ (10). In contrast, Lechner (42) reported that neonatally starved guinea pigs had completely recovered for lung volume after only 3 wk of subsequent refeeding. Guinea pigs, however, have more mature lungs at birth than rats (43).

Malnutrition starting in the neonatal period severely impairs lung growth, but to an apparently lesser degree than it does body weight. Refeeding brings about a dramatic catch-up in both body weight and lung volume and also restores the deviation from normal allometric relationship. The morphometric analysis presented in the companion study (17) adds further information as to structural and functional implications of these findings.

Acknowledgments. The authors gratefully thank J. Prodolliet from the Centre de Recherches of Nestlé Lausanne for the analyses of the milk samples. We acknowledge the helpful technical assistance of B. Haenni and C. Sperantia. We also wish to thank R. Shepherd for reading and E. de Peyer for typing our manuscript.

\section{REFERENCES}

1. Sahebjami H 1993 Nutrition and lung structure and function. Exp Lung Res 19:105124

2. Gaultier C 1991 Malnutrition and lung growth. Pediatr Pulmonol 10:278-286

3. Winick M, Noble A 1965 Quantitative changes in DNA, RNA, and protein during prenatal and postnatal growth in the rat. Dev Biol 12:451-466

4. Burri PH, Dbaly J, Weibel ER 1974 The postnatal growth of the rat lung. I. Morphometry. Anat Rec 178:711-730

5. Powell JT, Whitney PL 1980 Postnatal development of rat lung. Changes in lung lectin, elastin, acetylcholinesterase and other enzymes. Biochem J 188:1-8

6. Nardell EA, Brody JS 1982 Determinants of mechanical properties of rat lung during postnatal development. J Appl Physiol 53:140-148

7. Zeltner TB, Caduff JH, Gehr P, Pfenninger J, Burri PH 1987 The postnatal development and growth of the human lung. I. Morphometry. Respir Physiol 67:247-267

8. Burri PH, Weibel ER 1971 Morphometric estimation of pulmonary diffusion capacity. II. Effects of $\mathrm{PO}_{2}$ on the growing rat lung. Adaptation of the growing rat lung to hypoxia and hyperoxia. Respir Physiol 11:247-264

9. Hugonnaud C, Gehr P, Weibel ER, Burri PH 1977 Adaptation of the growing lung to increased oxygen consumption. II. Morphometric analysis. Respir Physiol 29:1-10

10. Winick M, Noble A 1966 Cellular response in rats during malnutrition at various ages. J Nutr 89:300-306

11. Frank L, Groseclose E 1982 Oxygen toxicity in newborn rats: the adverse effects of undernutrition. J Appl Physiol 55:1248-1255

12. Das RM 1984 The effects of intermittent starvation on lung development in suckling rats. Am J Pathol 117:326-332

13. Massaro D, Teich N, Maxwell S, Massaro GD, Whitney P 1985 Postnatal development of alveoli. Regulation and evidence for a critical period in rats. J Clin Invest 76:1297-1305

14. Kalenga M, Henquin JC 1987 Protein deprivation from the neonatal period impairs lung development in the rat. Pediatr Res 21:45-49

15. Kalenga M, Henquin JC 1987 Alteration of lung mechanics by protein calorie malnutrition in weaned rats. Respir Physiol 68:29-39

16. Doekel RC, Zwillich CW, Scoggin CH, Krugler M, Weil JV 1976 Clinical semistarvation: depression of hypoxic ventilatory response. N Engl J Med 295:358-361

17. Kalenga M, Tschanz, SA, Burri PH 1995 Protein deficiency and the growing rat lung. II. Morphometric analysis and morphology. Pediatr Res 37:789-795 
18. Kalenga M, Eeckhout Y 1989 Effects of protein deprivation from the neonatal period on lung collagen and elastin in the rat. Pediatr Res 26:125-127

19. Jelliffe DB, Jelliffe EF 1978 The volume and composition of human milk in poorly nourished communities. A review. Am J Clin Nutr 31:492-515

20. Babicky A, Novakova V 1986 Protein malnutrition of the lactating female rat: effect on maternal behavior and spontaneous weaning of young rats. Physiol Bohemoslov 35:456-463

21. Grigor MR, Allan JE, Carrington JM, Carne A, Geursen A, Young D, Thompson MP, Haynes EB, Coleman RA 1987 Effect of dietary protein and food restriction on milk production and composition, maternal tissues and enzymes in lactating rats. $\mathbf{J}$ Nutr 117:1247-1258

22. Fellows WD, Rasmussen KM 1984 Comparison of methods for obtaining milk samples from well-nourished and malnourished rats. Physiol Behav 33:761-763

23. Kurz G, Wallenfels K 1974a Lactose and other $\beta$-D-galactosides. In: Bergmeyer HU (ed) Methods of Enzymatic Analysis, Vol 3. Academic Press, New York, pp $1180-1184$

24. Kurz G, Wallenfels K $1974 b$ D-galactose. UV assay with galactose dehydrogenase. In: Bergmeyer HU (ed) Methods of Enzymatic Analysis, Vol 3. Academic Press, New York, pp 1279-1282

25. Helrich K 1990 Official Methods of Analysis. Association of Official Analytical Chemists, Arlington, VA, pp 71-72

26. Helrich K 1990 Official Methods of Analysis. Association of Official Analytical Chemists, Arlington, VA, pp 811-812

27. Scherle W $1970 \mathrm{~A}$ simple method for volumetry of organs in quantitative stereology. Mikroskopie 26:57-60

28. Armitage P and Berry G (eds) 1987 Statistical Methods in Medical Research. Blackwell Scientific Publications, London

29. Naismith DJ, Richardson DP, Pritchart AE 1982 The utilization of protein and energy during lactation in the rat, with particular regard to the use of fat accumulated during pregnancy. Br J Nutr 48:433-441

30. Friggens NC, Hay DEF, Oldham JD 1993 Interactions between major nutrients in the diet and the lactational performance of rats. Br J Nutr 69:59-71
31. Mueller AJ, Cox WM 1946 The effect of changes in diet on the volume and composition of rat milk. J Nutr 31:249-259

32. Crnic LS, Chase HP 1978 Models of infantile undernutrition in rats: effects on milk. J Nutr 108:1755-1760

33. Warman NL, Rasmussen KM 1983 Effects of malnutrition during the reproduction cycle on nutritional status and lactational performance of rat dams. Nutr Res 3:527-547

34. Sampson DA, Jansen, GR 1984 Protein and energy nutrition during lactation. Annu Rev Nutr 4:43-67

35. Hambraeus L 1980 Maternal diet and human milk composition. In: Aebi H, Whitehead R (eds) Maternal Nutrition during Pregnancy and Lactation. Hans Huber, Berne, pp 233-244

36. Sahebjami H, Vassallo CL 1980 Influence of starvation on enzyme-induced emphysema. J Appl Physiol 48:284-288

37. Sahebjami H, Wirman JA 1981 Emphysema-like changes in the lungs of starved rats Am Rev Respir Dis 124:619-624

38. Sahebjami H, MacGee J 1985 Effects of starvation on lung mechanics and biochemistry in young and old rats. J Appl Physiol 58:778-784

39. Kerr JS, Riley DJ, Lanza-Jacoby S, Berg RA, Spilker HC, Yu SY, Edelman NH 1985 Nutritional emphysema in the rat: influence of protein depletion and impaired lung growth. Am Rev Respir Dis 131:644-650

40. Matsui R, Thurlbeck WM, Fujita Y, Yu SY, Kida K 1989 Connective tissue, mechanical, and morphometric changes in the lung of weanling rats fed a low protein diet. Pediatr Pulmonol 7:159-166

41. Harkema JR, Mauderly JL, Gregory RE, Pickrell JA 1984 A comparison of starvation and elastase models of emphysema in the rat. Am Rev Respir Dis 129:584-591

42. Lechner AJ 1985 Perinatal age determines the severity of retarded lung development induced by starvation. Am Rev Respir Dis 131:638-643

43. Lechner AJ, Banchero N 1982 Advanced pulmonary development in newborn guinea pigs (Cavia porcellus). Am J Anat 163:235-246 